J. Dairy Sci. 95:2513-2522

http://dx.doi.org/10.3168/jds.2011-4921

(C) American Dairy Science Association ${ }^{\circledR}, 2012$.

\title{
Effects of presynchronization and length of proestrus on fertility of grazing dairy cows subjected to a 5-day timed artificial insemination protocol
}

\author{
E. S. Ribeiro, A. P. A. Monteiro, F. S. Lima, H. Ayres, R. S. Bisinotto, M. Favoreto, L. F. Greco, R. S. Marsola, \\ W. W. Thatcher, and J. E. P. Santos ${ }^{1}$ \\ Department of Animal Sciences, University of Florida, Gainesville 32611
}

\section{ABSTRACT}

The objectives were to compare the effects of 2 methods of presynchronization and 2 lengths of proestrus on fertility of grazing dairy cows subjected to a 5-d timed artificial insemination (AI) protocol at initiation of breeding season. Lactating dairy cows $(\mathrm{n}=1,754)$ from 3 seasonal grazing farms were blocked within farm by breed, parity, and days in milk (DIM). Study d 0 was considered the day of AI of cows in COS72 $(72 \mathrm{~h}$ of proestrus). Within each block, cows were randomly assigned to 1 of 2 presynchronization treatments: a $\mathrm{PGF}_{2 \alpha}$-based program, Presynch, consisting of 2 injections of $\mathrm{PGF}_{2 \alpha}$ administered on $\mathrm{d}-32$ and -18 , or a $\mathrm{PGF}_{2 \alpha}-\mathrm{GnRH}$-based program, Double-Ovsynch (DO), consisting of $\mathrm{GnRH}$ on $\mathrm{d}-25, \mathrm{PGF}_{2 \alpha}$ on $\mathrm{d}-18$, and GnRH on $\mathrm{d}-15$. Within each of the 2 presynchronization treatments, cows were randomly assigned to 1 of 2 lengths of proestrus within the 5 -d timed AI protocol, consisting of $\mathrm{GnRH}$ on $\mathrm{d}-8, \mathrm{PGF}_{2 \alpha}$ on $\mathrm{d}-3$ and -2 , and $\mathrm{GnRH}+\mathrm{AI}$ at either $58 \mathrm{~h}$ (COS58) or $72 \mathrm{~h}(\mathrm{COS} 72)$ after the $\mathrm{d}-3 \mathrm{PGF}_{2 \alpha}$ injection. Ovaries were scanned by ultrasonography twice, on $\mathrm{d}-42$ and -32 , to determine estrous cyclicity before enrollment in the study. Blood was sampled and analyzed for concentrations of estradiol on the day of AI. Pregnancies per AI (P/AI) were determined 30 and $65 \mathrm{~d}$ after AI. Presynchronization did not affect the concentration of estradiol at AI $(\mathrm{DO}=6.4$ vs. Presynch $=5.8 \mathrm{pg} / \mathrm{mL})$, detection of estrus at AI (20.8 vs. $25.9 \%$ ), or P/AI on d 30 (56.8 vs. $59.1 \%)$ and 65 (52.5 vs. $52.4 \%$ ) after the first AI. Cows receiving COS72 had increased concentration of estradiol (6.6 vs. $5.5 \mathrm{pg} / \mathrm{mL}$ ) and detection of estrus at AI (28.5 vs. $10.8 \%$ ) compared with cows receiving COS58. Length of proestrus did not affect $\mathrm{P} /$ AI on d $30(\operatorname{COS} 72=58.7$ vs. $\operatorname{COS} 58=56.1 \%)$ but, in Presynch cows, COS58 was detrimental to fertility on d 65 after AI (54.9 vs. 46.5\%). Pregnancy loss between gestational d 30 and 65 was greater for Presynch

Received September 11, 2011

Accepted December 19, 2011.

${ }^{1}$ Corresponding author: jepsantos@ufl.edu than for DO (7.6 vs. 11.3\%), but it was not affected by length of proestrus. Estrous cyclic cows had greater P/ AI than anovular cows on $d 30$ (61.7 vs. $35.1 \%)$ and 65 (56.1 vs. $30.7 \%$ ), but no interaction between estrous cyclic status and treatments was detected. Crossbred Holstein/Jersey cows had superior fertility than their purebred counterparts during the breeding season. The Presynch and DO protocols resulted in similar fertility with no overall difference between the presynchronization methods; however, limiting the length of proestrus to $58 \mathrm{~h}$ reduced $\mathrm{P} / \mathrm{AI}$ in the 5 -d timed AI protocol when cows had their estrous cycle presynchronized with Presynch but not with DO.

Key words: 5-day timed artificial insemination, grazing dairy cow, presynchronization, proestrus

\section{INTRODUCTION}

Timed AI protocols have been used to manage reproduction of grazing dairy cows particularly in seasonally breeding herds at the first postpartum AI to maximize the proportion of cows pregnant early in the breeding season. Timed AI ensures high submission to insemination, which is important in maintaining a concentrated calving pattern and maximizing profitability (McDougall, 2010). Therefore, development of programs that improve fertility of first AI is important. Presynchronization of the estrous cycle improved fertility of grazing dairy cows subjected to timed AI, and the benefit to pregnancy per AI (P/AI) was greater than the incorporation of progesterone during the synchronization program (Ribeiro et al., in press). Presynchronization increased the proportion of cows in diestrus and the ovulation to the first GnRH injection of the timed AI protocol (Ribeiro et al., in press). In fact, inducing cows to be in diestrus and to have follicle turnover when the timed AI program is initiated usually improves $\mathrm{P} / \mathrm{AI}$ (Moreira et al., 2001; Galvão et al., 2007; Bisinotto et al., 2010a).

Presynchronization programs based solely on $\mathrm{PGF}_{2 \alpha}$ injections such as the Presynch protocol (Moreira et al., 2001) target estrous cyclic cows to initiate the timed AI in early diestrus. However, these programs have limited 
or no benefits to fertility of anovular cows, because cows without a corpus luteum (CL) do not respond to $\mathrm{PGF}_{2 \alpha}$. Based on this concept, presynchronization protocols including the use of GnRH injections (Bello et al., 2006; Galvão et al., 2007; Souza et al., 2008) or progesterone supplementation (Chebel et al., 2006; Stevenson, 2011) have been proposed to induce estrous cyclicity in anovular cows and to better synchronize follicle development when the timed AI protocol is initiated. When compared with the Presynch protocol, presynchronization that incorporates a single $\mathrm{GnRH}$ injection with $\mathrm{PGF}_{2 \alpha}$ did not benefit fertility of dairy cows in confinement (Galvão et al., 2007) or in grazing farms (Ribeiro et al., 2011). However, when confined cows were subjected to the Double-Ovsynch protocol, P/AI was improved compared with that of cows subjected to Presynch (Souza et al., 2008). The increment in fertility caused by Double-Ovsynch was only observed in primiparous cows, which are more likely to be anovular at the end of voluntary waiting period than multiparous cows (Santos et al., 2009).

Another alternative to enhance fertility of dairy cows is to alter the length of proestrus and optimize the periovulatory concentrations of estradiol. This approach might be particularly important in the 5 -d timed AI protocol, which results in a smaller ovulatory follicle diameter, reduced concentrations of estradiol during proestrus, and a smaller proportion of cows in estrus on the day of AI (Santos et al., 2010). In beef cows subjected to the 5-d timed AI protocol, the benefits of reducing the interval from the first $\mathrm{GnRH}$ to the first $\mathrm{PGF}_{2 \alpha}$ of the program were only observed when proestrus was extended to $72 \mathrm{~h}$ (Bridges et al., 2008). When insemination was performed at $72 \mathrm{~h}$ after induction of CL regression, administration of $\mathrm{GnRH}$ at 56 or $72 \mathrm{~h}$ resulted in similar fertility in high-producing dairy cows (Bisinotto et al., 2010b), but not in dairy heifers, which benefited by lengthening the proestrus (Lima et al., 2011). The response to altering the length of proestrus might vary with method of presynchronization. The Double-Ovsynch protocol is expected to better synchronize follicle development at the beginning of the 5 -d timed AI protocol, which might make cows in this program less sensitive to changes in length of proestrus.

The objectives of the present study were to compare the effect of 2 methods of presynchronization and 2 lengths of proestrus on fertility responses of grazing dairy cows subjected to a 5-d timed AI protocol. The hypotheses were that presynchronization using DoubleOvsynch would improve P/AI of grazing dairy cows compared with Presynch, primarily because of a benefit in anovular cows. Furthermore, increasing the length of proestrus without altering the timing of insemination relative to GnRH would increase estradiol concentrations during proestrus, increase estrous expression, and improve $\mathrm{P} / \mathrm{AI}$ in cows subjected to the 5-d timed AI program.

\section{MATERIALS AND METHODS}

\section{Cows, Pasture, and Management}

The study was conducted in 3 commercial grazing dairy farms $(\mathrm{A}: \mathrm{n}=563 ; \mathrm{B}: \mathrm{n}=607 ; \mathrm{C}: \mathrm{n}=585)$ located in north central Florida. In herd A, all lactating cows in the herd were used, but in herds B (approximately 1,200 cows) and $\mathrm{C}$ (approximately 1,100 cows), only the first weekly cohort of cows assigned to the breeding season was used, which represented approximately half of the lactating cows in each herd. All farms were fallcalving herds and used similar genetics and management practices. The average milk production per cow was approximately $6,000 \mathrm{~kg} /$ lactation. In total, 1,754 lactating dairy cows (226 Holsteins, 424 Jerseys, and 1,104 crossbreds) were enrolled in the study for first postpartum AI. Crossbred cows were mostly composed of $\mathrm{F}_{1}(50 / 50)$ and $\mathrm{F}_{2}(25 / 75)$ generations of crossbreeding between Holstein and Jersey genetics. Different genetic groups were managed together in a pasturebased system in all farms. Cows were maintained under irrigated pasture paddocks of 2.7 ha and managed in a daily rotational program with a stocking rate of approximately 10 cows/ha. The pasture was composed of annual ryegrass (Lolium multiflorum Lam.) during winter and early spring, and 'Tifton 85' Bermudagrass (Cynodon spp.) during late spring and summer. Cows were offered variable amounts of concentrate ( 7 to 13 $\mathrm{kg} / \mathrm{cow}$ per day) during and immediately after each milking according to forage availability and stage of lactation. The concentrate was based on soybean hulls, citrus pulp, whole cottonseed, cottonseed hulls, corn gluten feed, corn meal, soybean meal, molasses, and a mineral-vitamin premix, and designed to contain approximately $15 \% \mathrm{CP}, 4.5 \%$ fat, and $28 \% \mathrm{NDF}$. Cows were milked twice daily.

\section{Experimental Design and Treatments}

Within farm, cows were blocked by breed, parity (primiparous and multiparous), and DIM. Within each block, cows were randomly assigned to 1 of 2 presynchronization treatments. Estrous cycles were presynchronized either with a $\mathrm{PGF}_{2 \alpha}$-based program (Presynch) or with a $\mathrm{PGF}_{2 \alpha}-\mathrm{GnRH}$-based program (DO). Cows in Presynch $(\mathrm{n}=872)$ received $225-\mathrm{mg}$ injections of $\mathrm{PGF}_{2 \alpha}$ (Lutalyse sterile solution; $5 \mathrm{mg} /$ 


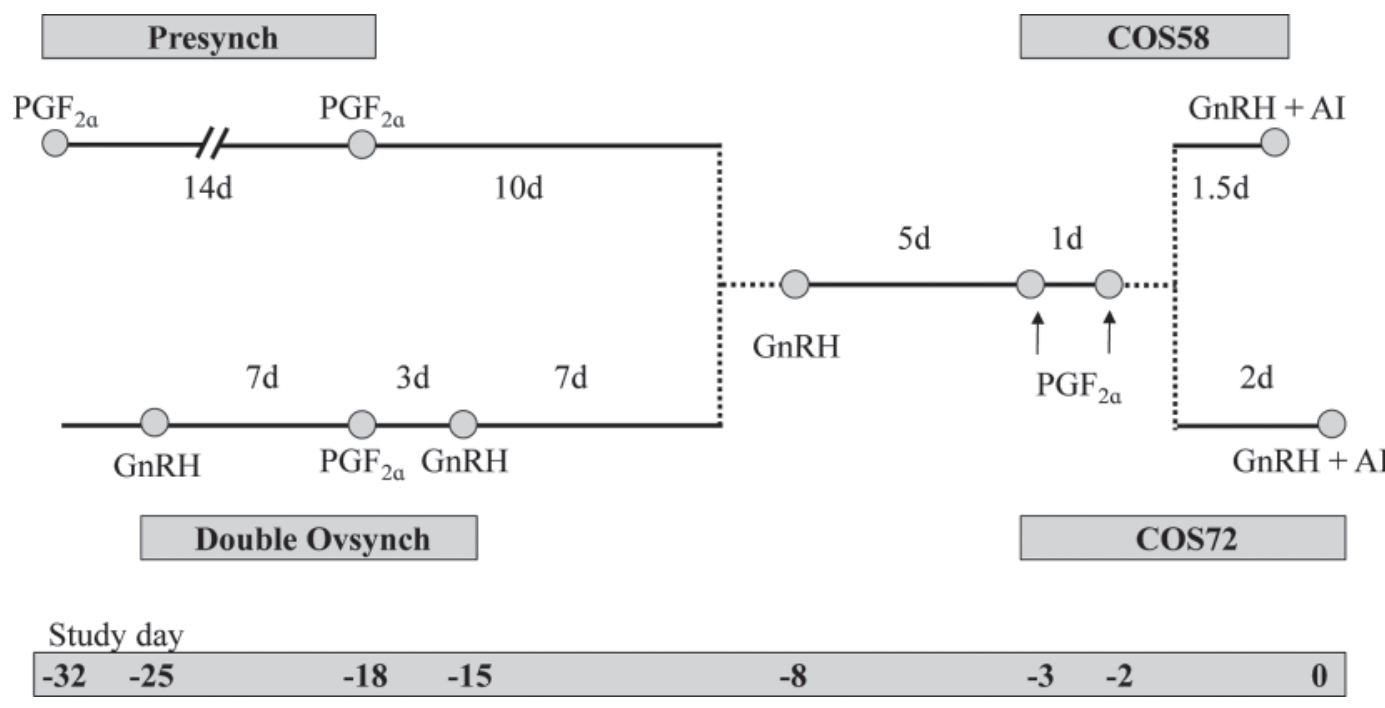

Figure 1. Diagram of activities in the study. Double Ovsynch $=$ presynchronization with the Ovsynch protocol; Presynch $=$ presynchronization with 2 injections of prostaglandin $\mathrm{F}_{2 \alpha}$ administered $14 \mathrm{~d}$ apart; COS58 $=58 \mathrm{~h}$ of proestrus; COS72 $=72 \mathrm{~h}$ of proestrus; GnRH $=$ injection of $100 \mu \mathrm{g}$ of gonadorelin; $\mathrm{PGF}_{2 \alpha}=$ injection of $25 \mathrm{mg}$ of prostaglandin $\mathrm{F}_{2 \alpha}$.

$\mathrm{mL}$ of dinoprost tromethamine, Pfizer Animal Health, Madison, NJ) administered $14 \mathrm{~d}$ apart and the timed AI protocol began $10 \mathrm{~d}$ later (Figure 1). Cows in DO (n $=882$ ) received a 100- $\mu$ g injection of GnRH (Fertagyl, $50 \mu \mathrm{g} / \mathrm{mL}$ gonadorelin diacetate tetrahydrate, Merck Animal Health, Summit, NJ) followed 7 d later by an injection of $25 \mathrm{mg}$ of $\mathrm{PGF}_{2 \alpha}$, and a second injection of GnRH $3 \mathrm{~d}$ after the $\mathrm{PGF}_{2 \alpha}$ injection; the timed AI protocol started $7 \mathrm{~d}$ later (Figure 1). Within each of the 2 presynchronization treatments, $30 \%$ of the cows were randomly assigned to $58 \mathrm{~h}$ of proestrus within the 5-d timed AI protocol and the remaining $70 \%$ assigned to $72 \mathrm{~h}$ of proestrus. The different proportions of cows assigned to the 2 lengths of proestrus allowed cows in the $58 \mathrm{~h}$ of proestrus to be inseminated before the afternoon milking when there was still sunlight. Cows in the $58 \mathrm{~h}$ of proestrus were inseminated within a 2-h period, whereas cows in the $72 \mathrm{~h}$ of proestrus were inseminated within a 3 -h period. Study d 0 for all cows was considered the day of AI of cows assigned to $72 \mathrm{~h}$ of proestrus. The 5 - $\mathrm{d}$ timed AI protocol consisted of an injection of $\mathrm{GnRH}$ on study $\mathrm{d}-8$, followed by 2 injections of $\mathrm{PGF}_{2 \alpha}$ on study $\mathrm{d}-3$ and -2 , and a second injection of GnRH concurrent with timed AI either 58 (COS58) or $72 \mathrm{~h}(\mathbf{C O S 7 2})$ after the $\mathrm{PGF}_{2 \alpha}$ on study $\mathrm{d}-3$ (Figure 1 ). This resulted in a $2 \times 2$ factorial arrangement of treatments with 4 treatment combinations: DO-COS58 ( $\mathrm{n}=252)$; DO-COS72 ( $\mathrm{n}=$ $630)$; Presynch-COS58 $(\mathrm{n}=258)$; and Presynch-COS72 $(\mathrm{n}=614)$. Inseminations were performed by the same 12 technicians on all farms and using the same 6 Jersey $(\mathrm{n}=1,477 \mathrm{AI})$ and 4 Holstein $(\mathrm{n}=277 \mathrm{AI})$ sires, which were balanced across all 4 treatments.

\section{Ovarian Ultrasonography and Determination of Estrous Cyclicity}

The ovaries of all cows were examined by ultrasonography (Easy Scan, BCF Technology, Livingston, UK) using a $7.5-\mathrm{MHz}$ linear transducer on study d -42 and -32 . Presence of CL in at least 1 of the 2 ultrasonographic examinations characterized an estrous cyclic cow, whereas lack of CL in both examinations characterized an anovular cow.

\section{Blood Samples and Estradiol Analysis}

Blood was sampled by puncture of the coccygeal vein or artery into evacuated tubes containing $\mathrm{K}_{2}$ EDTA (Becton Dickinson, Franklin Lakes, NJ) from 79 multiparous crossbred cows in one farm immediately before the final GnRH and AI (DO-COS58 = 20; DOCOS72 = 19; Presynch-COS58 = 21; Presynch-COS72 $=19$ ). Blood samples were immediately placed in ice and transported to the laboratory within $4 \mathrm{~h}$ of collection. Tubes were centrifuged at $2,000 \times g$ for $15 \mathrm{~min}$ for plasma separation. Plasma samples were frozen at $-30^{\circ} \mathrm{C}$ and later analyzed for their concentrations of estradiol by RIA using a commercial kit (Estradiol Double Antibody, Siemens Healthcare Diagnostics, Los Angeles, CA), which was previously validated for use in bovine samples (Siddiqui et al., 2009). Briefly, standards with concentrations of $0.39,0.78,1.56,3.12,6.25$, 12.5 , and $25.0 \mathrm{pg} / \mathrm{mL}$ were prepared by serial dilutions of estradiol (17 $\beta$-estradiol, Sigma Aldrich, St. Louis, MO) in steroid-free bovine plasma to create the standard curve. Plasma from a cow exhibiting spontaneous 
estrus and charcoal-stripped plasma from a 3-wk-old male calf were used as positive $(\sim 15.6 \mathrm{pg} / \mathrm{mL})$ and negative $(\sim 0.07 \mathrm{pg} / \mathrm{mL})$ controls, respectively. In addition, prepared samples with concentrations of 2.5, 5.0, and $10.0 \mathrm{pg} / \mathrm{mL}$ were incorporated into each assay to estimate the extraction efficiency.

Duplicate standards $(500 \mu \mathrm{L})$ and unknown plasma samples $(250 \mu \mathrm{L}$ diluted in $250 \mu \mathrm{L}$ of steroid-free plasma) had lipids extracted using $3.0 \mathrm{~mL}$ of diethyl ether. Samples were mixed in $13-\mathrm{mL}$ borosilicate tubes using a vortex mixer, allowed to settle for $1 \mathrm{~min}$ at room temperature, and then incubated at $-80^{\circ} \mathrm{C}$ for $30 \mathrm{~min}$. The supernatant with the extracted lipids in diethyl ether was then transferred to a $5.5-\mathrm{mL}$ borosilicate tube. The ether was allowed to evaporate overnight. The next morning, $0.5 \mathrm{~mL}$ of diethyl ether was pipetted into each tube to dissolve lipids attached to the tube wall and sediment them to the bottom to increase extraction recovery of estradiol. From this point, instructions of the commercial kit and reference validation (Siddiqui et al., 2009) were followed. The sensitivity of the assay was $0.15 \mathrm{pg} / \mathrm{mL}$, calculated at $2 \mathrm{SD}$ below the mean counts per minute at maximum binding. Samples were extracted and analyzed in duplicate and repeated when the CV between duplicates was $>15 \%$. Samples were analyzed in 3 assays. The average CV for all duplicates in the 3 assays was $9.0 \%$. For samples containing 2.5, 5.0 , and $10.0 \mathrm{pg} / \mathrm{mL}$ that were repeated throughout each assay, the intra-assay CV were, respectively, 12.0, 6.0 , and $4.0 \%$, and the inter-assay $\mathrm{CV}$ were, respectively, $12.0,10.0$, and $9.0 \%$.

\section{Detection of Estrus, BCS, and DIM}

On study $\mathrm{d}-2$, tailheads were painted using paint sticks (All-Weather Paintstick, LA-CO Industries, Chicago, IL), and removal of tailpaint was used as indicator of estrus on the day of timed AI. Cows were scored for BCS using a scale of 1 to $5(1=$ emaciated, $5=$ obese with 0.25 -unit increments; Ferguson et al., 1994) at AI and $30 \mathrm{~d}$ later. For statistical analysis, cows were categorized according to their BCS as thin when BCS $\leq 2.5$, moderate when between 2.75 and 3.00, and high when BCS $\geq 3.25$. Similarly, cows were categorized according to change in BCS from AI to pregnancy diagnosis as having lost BCS, no change in BCS, or having gained BCS. Cows were also categorized according to DIM at AI as low when DIM were between 35 and 60, moderate when between 61 and 90, and high when $>90$.

\section{Remaining Breeding Season}

After the first AI, cows on farm A were observed for estrus from d 19 to 29 after insemination and bulls were introduced on d 30 as described previously (Ribeiro et al., 2011). Briefly, the tailheads were painted with tailpaint on d 18 after the first AI and cows were observed once daily, after the morning milking, for signs of estrus based on removal of tailpaint. Cows in estrus were inseminated in the same morning. Tailpaint was re-applied as needed. On d 30, Jersey bulls were placed with all cows for additional $70 \mathrm{~d}$ of natural service to complete the 100-d breeding season. Bulls between 18 and 24 mo of age were used at a ratio of 1 bull for every 20 nonpregnant cows at the beginning of the natural service period. Subsequent inseminations for cows in farms B and C were not evaluated because either they were not re-inseminated or pregnancy diagnoses were not performed by decision of the farm.

\section{Pregnancy Diagnoses and Calculation of Reproductive Responses}

Pregnancy was diagnosed in all cows, despite reinsemination, via ultrasonography of the uterus and its content on study d 30, and it was characterized by visualization of a live embryo. Cows diagnosed as pregnant on d 30 were reexamined by transrectal palpation $35 \mathrm{~d}$ later. On farm A, reinseminated cows were examined by transrectal palpation between 36 and $46 \mathrm{~d}$ after AI. Pregnancies from natural service were diagnosed each $35 \mathrm{~d}$ after introduction of bulls, and age of pregnancy was estimated based on size of the amniotic vesicle either by ultrasound ( 28 to $35 \mathrm{~d}$ of gestation) or by transrectal palpation (36 to $63 \mathrm{~d}$ of gestation).

Pregnancy per AI for first insemination was calculated as the number of pregnant cows on d 30 and 65 divided by the total number of cows inseminated. Pregnancy loss was calculated for first AI as the number of cows that lost pregnancy between gestation $\mathrm{d} 30$ and 65 divided by the number of pregnant cows on d 30. Reinsemination on farm A was calculated as the number of nonpregnant cows on d 30 after the first AI that were reinseminated before introduction of the bulls. Pregnancy per AI for second insemination was calculated as the number of pregnant cows on gestation d $41 \pm$ 5 divided by the total number of cows reinseminated. Pregnancy during natural service was calculated as the number of cows pregnant to bulls divided by the number of cows that did not become pregnant to AI. Finally, pregnancy at the end of the study was calculated as the number of pregnant cows on d 65 after a breeding (AI or natural service) divided by the total number of cows enrolled in the study. For survival analysis, cows that were sold, died, or remained nonpregnant at the end of the 100-d breeding season were censored when the respective event occurred. 


\section{Statistical Analyses}

Binary data were analyzed using the generalized linear mixed model (GLIMMIX) procedure of SAS (version 9.2, SAS/STAT, SAS Institute Inc., Cary, NC) to allow for statistical models with fixed and random effects. A binary distribution was fitted and a logit link used in all models for categorical data. All statistical models included the fixed effects of method of presynchronization, length of proestrus, and interaction between presynchronization and proestrus. Farm was a random effect in all models. Univariate analyses were performed to select covariates (parity, breed of cow, DIM at first $\mathrm{AI}, \mathrm{BCS}$ at AI, BCS change from AI to d 30) based on significance $(P<0.10)$ to build multivariate models. For analyses of $\mathrm{P} / \mathrm{AI}$ on $\mathrm{d} 30$ and 65 and pregnancy loss, the effects of sire, technician, and estrous cyclicity were evaluated by univariate analyses before inclusion in the final models. Multivariate models were then created with covariates that were significant from the univariate analyses. Individual covariates were removed from the multivariate models in a stepwise fashion if $P$ $>0.10$. Method of presynchronization, length of proestrus, and interaction between presynchronization and length of proestrus were forced in the final multivariate models. Model fitting was assessed using the fit statistics of GLIMMIX.

Concentration of estradiol at AI and interval to re-insemination in cows rebred by $\mathrm{AI}$ in farm $\mathrm{A}$ were analyzed by ANOVA using the GLM procedure of SAS. The statistical models included the effects of method of presynchronization, length of proestrus, interaction between presynchronization and length of proestrus, parity, breed of cow, estrous cyclic status, and interaction between method of presynchronization and parity and estrous cyclic status.

Interval to pregnancy on farm A was analyzed by the Cox proportional hazard model using the PHREG procedure of SAS. The adjusted hazard ratio and respective $95 \%$ CI were calculated. The time variable used in the model was the interval in days between study $\mathrm{d}$ 0 and pregnancy or when a cow was censored because she was sold, died, or remained nonpregnant on study d 100. Pregnancy was considered based on diagnoses performed $65 \mathrm{~d}$ after AI to account for pregnancy losses between 30 and $65 \mathrm{~d}$ of gestation. The statistical model included the effects of method of presynchronization, length of proestrus, interaction between presynchronization and length of proestrus, parity, breed of cow, DIM at first AI, BCS at AI, BCS change from AI to d 30, estrous cyclic status, and interactions between presynchronization and parity, breed, and estrous cyclic status. A stepwise backward elimination was used to remove covariates when $P>0.10$. Method of presynchro- nization and length of proestrus were forced in the final models. Proportionality was assessed by evaluating the Kaplan-Meier curves. The median and mean days to pregnancy were obtained from the LIFETEST procedure of SAS. Survival graphs were generated with the MedCalc version 9.2 (MedCalc Software, Mariakerke, Belgium). Differences with $P \leq 0.05$ were considered significant and $0.05<P \leq 0.10$ were considered tendencies.

\section{RESULTS}

The body condition of cows did not differ with treatments, and the mean $( \pm \mathrm{SD})$ and median BCS were, respectively, $2.97 \pm 0.34$ and 3.00 at AI, and $3.10 \pm 0.41$ and 3.00 on study d 30 . The proportion of anovular cows in the study was $14.1 \%$, ranging from 8.0 to $20.2 \%$ according to farm. The proportions of estrous cyclic cows did not differ with method of presynchronization $(\mathrm{DO}=85.8$ vs. Presynch $=85.9 \% ; P=0.64)$, length of proestrus $(\operatorname{COS} 58=84.7$ vs. $\operatorname{COS} 72=86.3 \% ; P=$ 0.46 ), or breed of cows (Holstein $=89.4$ vs. Jersey $=$ 77.4 vs. crossbred $=88.4 \% ; P=0.28)$. As expected, estrous cyclicity was influenced $(P<0.01)$ by parity (multiparous $=91.3$ vs. primiparous $=80.0 \% ; P<$ 0.01 ), BCS at AI (thin $=66.3$ vs. moderate $=84.9$ vs. high $=96.3 \%$ ), and DIM at AI (low $=57.3$ vs. moderate $=81.6$ vs. high $=92.1 \%$ ).

\section{Estrus at Al and Estradiol Concentrations}

Method of presynchronization did not affect the concentration of estradiol at AI or the proportion of cows in estrus at AI (Table 1). Conversely, cows receiving COS72 had increased estradiol concentration (COS72 $=6.61 \pm 0.46$ vs. $\operatorname{COS} 58=5.53 \pm 0.39 \mathrm{pg} / \mathrm{mL} ; P=$ $0.04)$ and detection of estrus (COS72 $=28.5$ vs. COS58 $=10.8 \% ; P<0.001)$ at AI compared with cows in COS58 (Table 1). No interaction was observed between method of presynchronization and length of proestrus on estradiol concentration and detection of estrus at AI. Estrous cyclic cows had greater $(P<0.001)$ concentration of estradiol at AI than anovular cows, but the proportion of cows detected in estrus at AI was not influenced by estrous cyclic status (Table 2). No interaction between estrous cyclic status and method of presynchronization was detected for estradiol concentration and detection of estrus at AI. It is interesting to note that the concentrations of estradiol did not differ between cows observed or not in estrus at AI, but they were greater $(P<0.01)$ in cows that became pregnant than those nonpregnant on d 30 after AI $(8.2 \pm 0.5$ vs. $5.5 \pm 0.6 \mathrm{pg} / \mathrm{mL})$. 
Table 1. Effects of presynchronization protocol and length of proestrus on reproductive outcomes of lactating grazing dairy cows after first insemination

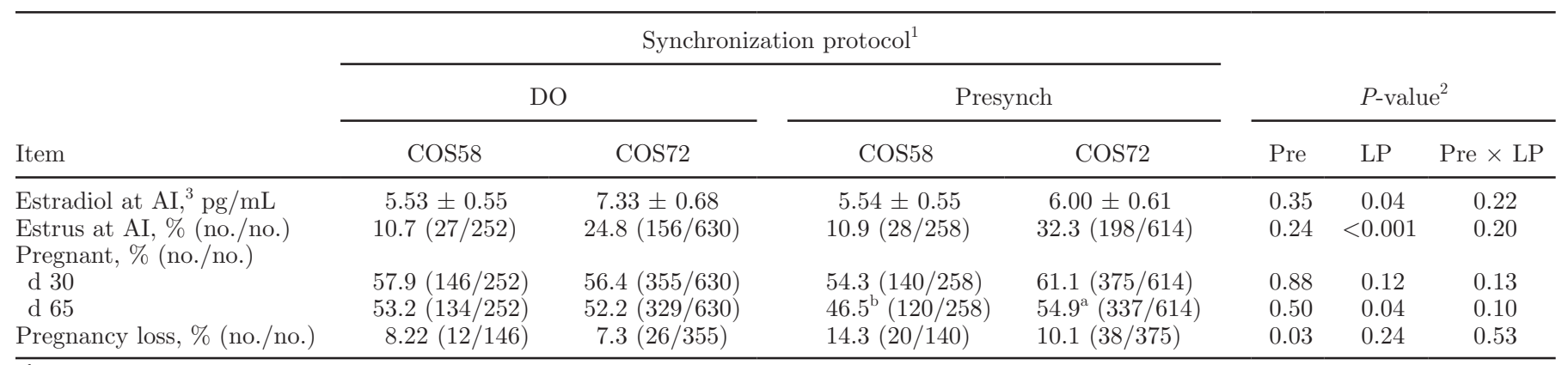

${ }_{\mathrm{a}, \mathrm{b}}$ Means within a row with different superscripts differ $(P<0.05)$.

${ }^{1}$ All cows were subjected to the 5-d timed AI protocol. Cows in the Double-Ovsynch (DO) protocol received an injection of GnRH followed 7 $\mathrm{d}$ later by $\mathrm{PGF}_{2 \alpha}, 3 \mathrm{~d}$ later $\mathrm{GnRH}$, and the 5-d timed AI started $7 \mathrm{~d}$ later. Cows in Presynch received 2 injections of PGF $2 \alpha$ administered $14 \mathrm{~d}$ apart, and the 5-d timed AI protocol started $10 \mathrm{~d}$ after the second $\mathrm{PGF}_{2 \alpha}$. Cows assigned to COS58 received the final GnRH injection concurrent with timed $\mathrm{AI}$ at $58 \mathrm{~h}$ after induction of luteolysis, whereas those assigned to COS72 received both $\mathrm{GnRH}$ and timed $\mathrm{AI}$ at $72 \mathrm{~h}$.

${ }^{2}$ Pre $=$ effect of presynchronization (DO vs. Presynch); LP $=$ effect of length of proestrus (COS58 vs. COS72); Pre $\times$ LP $=$ interaction between Pre and LP.

${ }^{3}$ Least squares means \pm SEM.

\section{Pregnancy per Al and Pregnancy Loss}

Presynchronization treatment did not affect $\mathrm{P} / \mathrm{AI}$ on d 30 and 65 after insemination and, overall, 56.8 and $59.1 \%$ of the DO and Presynch cows were pregnant on d 30 (Table 1). Length of proestrus did not affect P/AI on $\mathrm{d}$ 30. However, a tendency for an interaction $(P=$ $0.10)$ between presynchronization treatment and length of proestrus was detected for $\mathrm{P} / \mathrm{AI}$ on $\mathrm{d} 65$. For cows in DO, altering the length of proestrus had no effect on $\mathrm{P} / \mathrm{AI}$, but for Presynch, reducing the proestrus to $58 \mathrm{~h}$ compromised fertility. Pregnancy loss was greater $(P=$ 0.03) for Presynch than for DO, but no effects of length of proestrus or interaction between presynchronization treatment and length of proestrus were observed.
Anovular cows had worse $(P<0.001) \mathrm{P} /$ AI than estrous cyclic cows on d 30 and 65 after AI, but no interactions were detected between estrous cyclicity and presynchronization treatment (Table 2) or length of proestrus. The risk of pregnancy loss did not differ with estrous cyclicity status. Parity did not affect $\mathrm{P} / \mathrm{AI}$ on $\mathrm{d} 30$ (primiparous $=54.0$ vs. multiparous $=$ $60.7 \%, P=0.74$ ) or on $\mathrm{d} 65$ (primiparous $=48.5$ vs. multiparous $=55.2 \%, P=0.82$ ), and no interactions $(P>0.18)$ were observed between parity and method of presynchronization or length of proestrus on P/AI. The BCS of cows at AI and the change in BCS from AI to d 30 influenced $(P<0.001) \mathrm{P} / \mathrm{AI}$. On d 65 after AI, $\mathrm{P} / \mathrm{AI}$ increased $(P<0.001)$ with increasing BCS (BCS $\leq 2.5=31.7$ vs. $\mathrm{BCS} 2.75$ to $3.0=51.6$ vs. $\mathrm{BCS} \geq 3.25$

Table 2. Effects of method of presynchronization ${ }^{1}$ and estrous cyclicity status on reproductive responses of grazing dairy cows

\begin{tabular}{|c|c|c|c|c|c|c|c|}
\hline \multirow[b]{2}{*}{ Item } & \multicolumn{4}{|c|}{ Estrous cyclicity $^{2}$} & & & \\
\hline & DO & Presynch & $\mathrm{DO}$ & Presynch & $\mathrm{EC}$ & Pre & $\mathrm{EC} \times$ Pre \\
\hline Estradiol at $\mathrm{AI},{ }^{4} \mathrm{pg} / \mathrm{mL}$ & $4.91 \pm 0.67$ & $4.27 \pm 0.62$ & $8.24 \pm 0.54$ & $7.72 \pm 0.52$ & $<0.001$ & 0.35 & 0.74 \\
\hline Estrus at AI, \% (no./no.) & $20.0(25 / 125)$ & $26.0(32 / 123)$ & $20.9(158 / 757)$ & $25.9(194 / 749)$ & 0.50 & 0.24 & 0.85 \\
\hline \multicolumn{8}{|l|}{ Pregnant, \% (no./no.) } \\
\hline \multicolumn{8}{|c|}{$\begin{array}{l}{ }^{1} \text { All cows were subjected to the } 5 \text {-d timed } \mathrm{AI} \text { protocol. Cows in the Double-Ovsynch (DO) protocol received an injection of GnRH followed } 7 \\
\mathrm{~d} \text { later by } \mathrm{PGF}_{2 \alpha}, 3 \mathrm{~d} \text { later GnRH, and the } 5 \text {-d timed AI started } 7 \mathrm{~d} \text { later. Cows in Presynch received } 2 \text { injections of } \mathrm{PGF}_{2 \alpha} \text { administered } 14 \mathrm{~d} \\
\text { apart, and the } 5 \text {-d timed AI protocol started } 10 \mathrm{~d} \text { after the second } \mathrm{PGF}_{2 \alpha} \text {. }\end{array}$} \\
\hline \multicolumn{8}{|c|}{$\begin{array}{l}{ }^{2} \text { Anovular }=\text { lack of corpus luteum }(\mathrm{CL}) \text { in } 2 \text { sequential ultrasound exams } 10 \mathrm{~d} \text { apart; Cyclic }=\text { presence of a CL in at least } 1 \text { of the } 2 \mathrm{ultrasound} \\
\text { exams. }\end{array}$} \\
\hline${ }^{3} \mathrm{EC}=$ effect of estrous cyclic & Pre $=$ effect of & thod of presvnc & zation; $\mathrm{EC} \times$ Pre & interaction betwe & $\mathrm{EC}$ and $\mathrm{P}$ & & \\
\hline
\end{tabular}


$=63.3 \%)$. Similarly, cows that gained BCS in the first $30 \mathrm{~d}$ after insemination had greater $\mathrm{P} / \mathrm{AI}$ than those that maintained or lost BCS (gained $=56.7$ vs. no change $=48.6$ vs. lost $=48.9 \%$ ). Fertility responses of cows of different breeds were not influenced by method of presynchronization (Figure 2) or length of proestrus. Although P/AI did not differ among Jerseys, Holsteins, and crossbreds, pregnancy loss was less $(P=0.02)$ for crossbreds $(7.7 \%)$ than for Jerseys $(12.8 \%)$ and Holsteins (13.6\%; Figure 2).

\section{Reproduction in the Entire Breeding Season on Farm A}

The initial treatments had no effect on the remaining breeding season. The proportion of nonpregnant cows on d 30 that had been detected in estrus and reinseminated was not influenced $(P=0.28)$ by method of presynchronization $(\mathrm{DO}=68.4$ vs. Presynch $=57.8 \%)$. Breed of cows and estrous cyclic status influenced $(P$ $<0.001)$ the proportion of cows observed in estrus and re-inseminated. Re-insemination did not differ between Holsteins and Jerseys, but crossbred cows had greater $(P=0.05)$ detection of estrus and re-insemination than Holsteins, and tended $(P=0.07)$ to be greater than Jerseys (crossbred $=68.2$ vs. Jersey $=45.0$ vs. Holstein $=35.7 \%)$. Similarly, estrous cyclic cows had greater $(P$ $<0.001$ ) detection of estrus and re-insemination than anovular cows (68.6 vs. $34.5 \%$ ).
The rate of pregnancy throughout the 100-d breeding season was not affected by treatment (Table 3). In fact, the median and mean intervals to pregnancy were similar between presynchronization treatments and between lengths of proestrus. Factors that influenced pregnancy rate were breed of cow, BCS at AI, BCS change, and estrous cyclicity. Although pregnancy rate did not differ between Jerseys and Holsteins, the hazard of pregnancy was $51 \%$ greater $(P=0.05)$ for crossbred cows than for Holstein cows. Cows with BCS at AI $>3.00$ had increased $(P<0.01)$ hazard of pregnancy compared with those with BCS $\leq 3.00$. Similarly, cows that gained body condition from study d 0 and 30 had greater $(P<0.01)$ hazard of pregnancy than cows that lost or maintained body condition. Finally, estrous cyclic cows had $79 \%$ greater hazard of pregnancy than anovular cows, which reduced the median and mean days to pregnancy by 35 and $12 \mathrm{~d}$, respectively.

\section{DISCUSSION}

Presynchronization of the estrous cycle improves fertility of high-producing dairy cows subjected to timed AI protocols (Moreira et al., 2001), and this benefit has also been shown in cows in grazing dairy farms (Ribeiro et al., in press). Similarly, altering the length of proestrus in timed AI protocols by manipulating the interval between induction of luteolysis with $\mathrm{PGF}_{2 \alpha}$ and induction of the luteinizing hormone surge with GnRH can

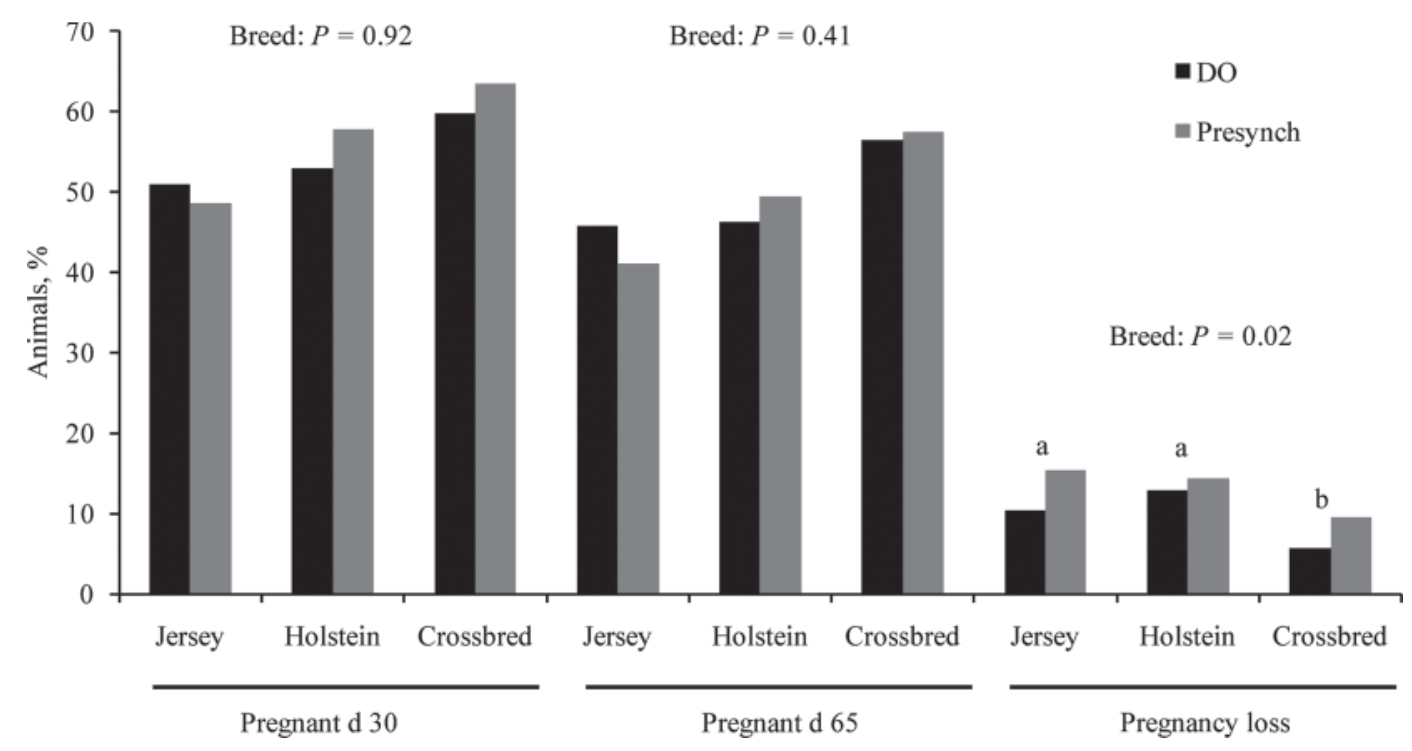

Figure 2. Pregnancy per AI and pregnancy loss of grazing dairy cows at first insemination according to breed and presynchronization treatments in 3 seasonal grazing farms. All cows were subjected to the 5-d timed AI protocol. Cows in the Double-Ovsynch (DO) protocol received an injection of $\mathrm{GnRH}$ followed $7 \mathrm{~d}$ later by $\mathrm{PGF}_{2 \alpha}, 3 \mathrm{~d}$ later $\mathrm{GnRH}$, and the 5-d timed AI started $7 \mathrm{~d}$ after the second GnRH of the presynchronization. Cows in Presynch received 2 injections of $\mathrm{PGF}_{2 \alpha}$ administered $14 \mathrm{~d}$ apart and the 5-d timed AI protocol started $10 \mathrm{~d}$ after the second $\mathrm{PGF}_{2 \alpha}$. Jersey, $\mathrm{n}=424$; Holstein, $\mathrm{n}=226$; crossbred, $\mathrm{n}=1,104$. Different letters $(\mathrm{a}, \mathrm{b})$ indicate a difference among breeds $(P<0.05)$. 
Table 3. Cox proportional hazard model for pregnancy rate of grazing dairy cows in farm A

\begin{tabular}{|c|c|c|c|c|}
\hline \multirow[b]{2}{*}{ Item } & \multicolumn{2}{|c|}{ Days to pregnancy } & \multirow[b]{2}{*}{$\begin{array}{c}\mathrm{AHR}^{1} \\
(95 \% \mathrm{CI})\end{array}$} & \multirow[b]{2}{*}{$P$-value } \\
\hline & $\begin{array}{l}\text { Median } \\
(95 \% \text { CI })\end{array}$ & $\begin{array}{c}\text { Mean } \\
\pm \text { SEM }\end{array}$ & & \\
\hline \multicolumn{5}{|c|}{ Presynchronization $^{2}$} \\
\hline Presynch & $0(0-0)$ & $21.2 \pm 1.8$ & Referent & - \\
\hline $\mathrm{DO}$ & $0(0-0)$ & $20.8 \pm 1.8$ & $1.09(0.91-1.30)$ & 0.34 \\
\hline \multicolumn{5}{|c|}{ Length of proestrus ${ }^{2}$} \\
\hline COS58 & $0(0-0)$ & $21.8 \pm 1.7$ & Referent & - \\
\hline COS72 & $0(0-0)$ & $20.8 \pm 2.0$ & $1.00(0.84-1.19)$ & 0.98 \\
\hline \multicolumn{5}{|l|}{ Breed } \\
\hline Holstein & $22(0-60)$ & $31.0 \pm 6.0$ & Referent & \\
\hline Jersey & $0(0-26)$ & $25.0 \pm 4.2$ & $1.25(0.77-2.02)$ & 0.36 \\
\hline Crossbred & $0(0-0)$ & $20.2 \pm 1.4$ & $1.51(1.00-2.26)$ & 0.05 \\
\hline \multicolumn{5}{|l|}{$\mathrm{BCS}$ at $\mathrm{AI}$} \\
\hline$\leq 3.00$ & $0(0-21)$ & $27.0 \pm 2.1$ & Referent & \\
\hline$>3.00$ & $0(0-0)$ & $16.2 \pm 1.6$ & $1.27(1.06-1.52)$ & $<0.01$ \\
\hline \multicolumn{5}{|l|}{ BCS change ${ }^{3}$} \\
\hline Lost & $0(0-20)$ & $24.0 \pm 2.6$ & Referent & \\
\hline No change & $0(0-20)$ & $24.8 \pm 2.4$ & $1.03(0.82-1.29)$ & 0.81 \\
\hline Gained & $0(0-0)$ & $15.4 \pm 1.8$ & $1.35(1.08-1.68)$ & $<0.01$ \\
\hline \multicolumn{5}{|c|}{ Estrous cyclicity $^{4}$} \\
\hline Anovular & $35(22-45)$ & $34.3 \pm 4.2$ & Referent & \\
\hline Cyclic & $0(0-0)$ & $22.1 \pm 1.4$ & $1.79(1.25-2.55)$ & $<0.001$ \\
\hline \multicolumn{5}{|c|}{${ }^{1} \mathrm{AHR}=$ adjusted hazard ratio. } \\
\hline \multicolumn{5}{|c|}{ 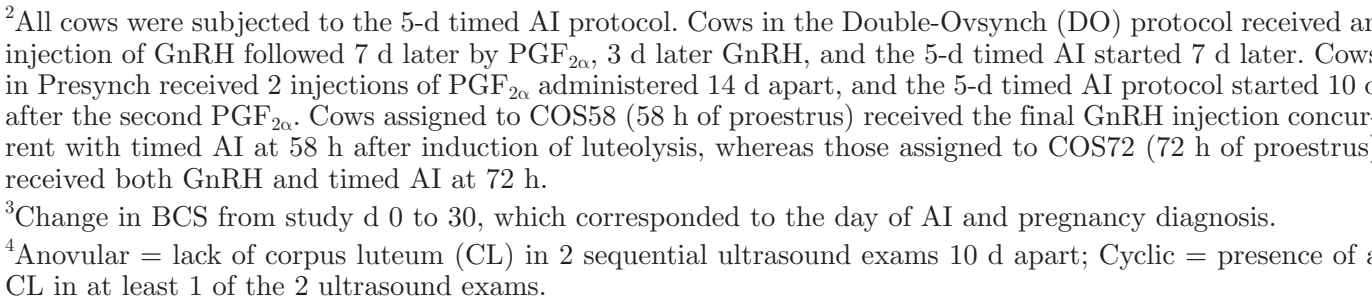 } \\
\hline
\end{tabular}

also affect fertility of dairy cows, particularly when the interval is too short, and limit the growth and steroidogenesis of the ovulatory follicle during proestrus (Peters and Pursley, 2003).

In the current study, 2 methods of presynchronization of the estrous cycle combined with 2 lengths of proestrus in cows subjected to the 5 -d timed AI program were evaluated. The rational for the DO program was that $\mathrm{GnRH}$ is very efficacious at inducing ovulation in anovular cows (Gümen et al., 2003), and prevalence of anovular cows is usually high in dairy herds before the first postpartum insemination (Rhodes et al., 2003; Santos et al., 2009). On the other hand, Presynch is commonly used to benefit fertility of estrous cyclic cows subjected to timed AI programs (Moreira et al., 2001), and it has been shown to result in similar fertility compared with cows receiving presynchronization with combinations of a single $\mathrm{GnRH}$ and $\mathrm{PGF}_{2 \alpha}$ (Galvão et al., 2007; Ribeiro et al., 2011). Despite the potential benefits of the DO in more precisely synchronizing ovulation and inducing estrous cyclicity in anovular cows, estradiol concentrations at AI, detection of estrus at $\mathrm{AI}$, and $\mathrm{P} / \mathrm{AI}$ on $\mathrm{d} 30$ and 65 did not differ between the 2 presynchronization treatments. Although cows in the DO had less pregnancy loss than cows synchronized with the Presynch, overall fertility was similar between the 2 presynchronization treatments.

Large epidemiological studies have reported that the prevalence of anovular cows ranges from 18 to $43 \%$ at the beginning of the breeding season in different grazing herds (Rhodes et al., 2003) and at the end of the voluntary waiting period in confinement dairy farms (Santos et al., 2009). Anovular cows have reduced fertility at first AI (Santos et al., 2009) and increased risk or pregnancy loss (Santos et al., 2004), all of which result in reduced rate of pregnancy throughout the breeding period (Ribeiro et al., 2011). Primiparous cows are more likely to remain anovular at the end of the voluntary waiting period. When the DO resulted in greater $\mathrm{P} / \mathrm{AI}$ in high-producing dairy cows, all the benefit originated from cows in first lactation (Souza et al., 2008). In that study, estrous cyclic status was not evaluated before enrollment in the timed AI protocols, but it is plausible to suggest that some of the benefit of DO compared with Presynch in primiparous cows could have been caused by the greater risk of anovulation in that category of cows, making them nonresponsive to the Presynch. Surprisingly, compared with Presynch, 
DO did not influence $\mathrm{P} / \mathrm{AI}$ of grazing cows and a lack of benefit was observed regardless of parity and estrous cyclic status. Despite having fewer pregnancy losses between 30 and $65 \mathrm{~d}$ of gestation, cows in DO did not have a greater probability of pregnancy on d 65 after insemination compared with Presynch cows. Perhaps the limited number of anovular cows in the study (248, $14.1 \%$ ) restricted the benefit of DO in inducing estrous cyclicity and increasing the proportion of cows in diestrus when the 5-d timed AI initiated.

Most anovular cows respond to GnRH by ovulating a follicle (Gümen et al., 2003), suggesting that incorporation of GnRH for presynchronization was expected to induce estrous cyclicity and benefit fertility. A critical factor affecting fertility of anovular cows seems to be the low concentration of progesterone during the development of the ovulatory follicle (Bisinotto et al., 2010a). Therefore, induction of ovulation and, consequently, formation of a CL before enrollment in the timed AI program would benefit fertility of anovular cows by increasing the proportion of cows in diestrus when the first $\mathrm{GnRH}$ of the timed $\mathrm{AI}$ is administered (Ribeiro et al., 2011). When estrous cyclic cows developed the ovulatory follicle under low concentrations of progesterone, $\mathrm{P} / \mathrm{AI}$ and pregnancy loss were similar to those of anovular cows (Bisinotto et al., 2010a). Surprisingly, DO did not influence fertility of anovular cows when compared with Presynch. In previous studies by our group with high-producing cows in confinement (Galvão et al., 2007) or with low-producing cows on pasture (Ribeiro et al., 2011), use of a $\mathrm{PGF}_{2 \alpha} / \mathrm{GnRH}$ combination for presynchronization was not superior to Presynch, despite a greater proportion of cows in diestrus at the beginning of the timed AI protocol when presynchronization used GnRH (Ribeiro et al., 2011). Collectively, these data suggest that simply inducing ovulation and formation of a CL in anovular cows before enrollment in the timed AI program does not seem to resolve the underlying problem of their low fertility, particularly in grazing cows (Ribeiro et al., 2011).

Extending proestrus from 58 to $72 \mathrm{~h}$ in the 5 -d timed AI resulted in greater estradiol concentrations and expression of estrus at AI, which are often associated with improved fertility in cows in timed AI programs (Santos et al., 2010). In fact, pregnant cows had greater concentration of estradiol at AI than nonpregnant cows in the present study. Lengthening proestrus did not influence fertility on d 30 after AI; however, on d 65, the restricted proestrus of $58 \mathrm{~h}$ reduced $\mathrm{P} / \mathrm{AI}$ of cows presynchronized with $\mathrm{PGF}_{2 \alpha}$ only. For cows enrolled in DO, however, altering the length of proestrus did not affect fertility. When cows receive presynchronization with $\mathrm{GnRH}$, more of them are in diestrus when the timed AI is initiated (Ribeiro et al., 2011), and ovulatory responses during the timed AI are usually high (Bello et al., 2006). The increased precision of synchronization with the DO, as suggested by some (Souza et al., 2008), might result in dominant follicles that are more homogeneous in development and less susceptible to restrictions in length of proestrus. Upon further evaluation, we observed that most of the reduction in $\mathrm{P} / \mathrm{AI}$ for Presynch cows with $58 \mathrm{~h}$ of proestrus was observed in those that did not display signs of estrus at AI. In those cows, P/AI were 44.8 versus $50.7 \%$ for COS58 and COS72, respectively, whereas for cows in estrus, the $\mathrm{P} / \mathrm{AI}$ were, respectively, 60.7 and $63.6 \%$ for COS58 and COS72. It is possible that for cows in the Presynch, reducing proestrus limited exposure to estradiol and compromised fertility.

Pregnancies per AI in the current study were generally high, and the results from the first AI were not influenced by breed. Approximately $63 \%$ of the cows in the study were crossbreds, and these cows had generally superior fertility than purebred Holsteins or Jerseys. Improving fertility to AI programs ensures that more cows will become pregnant to superior sires that allow selection not only for production, but also for reproduction and health traits. This might be particularly important in grazing herds utilizing crossbreeding because AI permits selection of a specific breed of sire to be used in the cows to perpetuate a certain degree of hybrid vigor. Following the first $30 \mathrm{~d}$ of $\mathrm{AI}$ on farm A, $71.6 \%$ of the crossbred cows were pregnant compared with only $59 \%$ of the Jerseys and Holsteins. Such cows that become pregnant early in the breeding season and to proven sires, as opposed to natural service, are likely to be more profitable to producers in grazing farms (McDougall and Compton, 2006). In New Zealand, becoming pregnant early in the breeding season ensures a longer lactation that has marked effects on production and profitability of the cow (McDougall and Compton, 2006). A similar response was observed by Ribeiro et al. (2011) in which crossbred Holstein/Jersey cows had superior reproductive performance than either 1 of the 2 breeds on grazing farms. Therefore, it is plausible to suggest that crossbred Holstein/Jersey cows have superior reproductive performance than their purebred counterparts when subjected to grazing. Perhaps they are a better match to an environment that has more limitations to nutrition, or simply because crossbreeding reduces inbreeding and adds hybrid vigor, both of which have been suggested to improve health and reproduction in cattle (Harris and Kolver, 2001).

\section{CONCLUSIONS}

Method of presynchronization with only $\mathrm{PGF}_{2 \alpha}$ in Presynch or with a combination of $\mathrm{GnRH} / \mathrm{PGF}_{2 \alpha}$ in 
DO resulted in similar fertility in grazing dairy cows at first AI and a similar rate of pregnancy throughout the 100-d breeding season. Extending proestrus from 58 to $72 \mathrm{~h}$ in the 5-d timed AI protocol resulted in greater estradiol concentrations and expression of estrus at AI regardless of the method of presynchronization. Nevertheless, restricting proestrus to $58 \mathrm{~h}$ reduced fertility of cows enrolled in the Presynch protocol but not the DO protocol. Anovular cows had reduced concentrations of estradiol at AI, P/AI at first AI, detection of estrus and re-insemination by AI, and pregnancy to natural service, all of which resulted in a marked decrease in the rate of pregnancy and extension of days open. Interestingly, incorporating GnRH for presynchronization did not benefit reproductive performance of anovular cows. Fertility of cows was better when they had BCS at $\mathrm{AI}>3.00$ or gained body condition after AI (or both). Finally, crossbred cows generally had better reproductive performance than Holsteins or Jerseys. In summary, the 2 methods of presynchronization and the 2 lengths of proestrus resulted in similar fertility in grazing dairy cows either at first AI or throughout the breeding season, and selection of one program over another will likely depend on ease of implementation.

\section{ACKNOWLEDGMENTS}

The authors thank the owner and staff of Piedmont, South Point, and Watson Dairies (Trenton, FL) for use of their cows and facilities. The assistance of Nilo Francisco, Pat Cilo Cilo, and Cliff Reindl (of Alliance Dairies, Trenton, FL) is greatly appreciated.

\section{REFERENCES}

Bello, N. M., J. P. Steibel, and R. J. Pursley. 2006. Optimizing ovulation to first $\mathrm{GnRH}$ improved outcomes to each hormonal injection of Ovsynch in lactating dairy cows. J. Dairy Sci. 89:3413-3424.

Bisinotto, R. S., R. C. Chebel, and J. E. P. Santos. 2010a. Follicular wave of the ovulatory follicle and not cyclic status influences fertility of dairy cows. J. Dairy Sci. 93:3578-3587.

Bisinotto, R. S., E. S. Ribeiro, L. T. Martins, R. S. Marsola, L. F. Greco, M. G. Favoreto, C. A. Risco, W. W. Thatcher, and J. E. P. Santos. 2010b. Effect of interval between induction of ovulation and artificial insemination (AI) and supplemental progesterone for resynchronization on fertility of dairy cows subjected to a 5-d timed AI program . J. Dairy Sci. 93:5798-5808.

Bridges, G. A., L. A. Helser, D. E. Grum, M. L. Mussard, C. L. Gasser, and M. L. Day. 2008. Decreasing the interval between GnRH and $\mathrm{PGF}_{2 \alpha}$ from 7 to 5 days and lengthening proestrus increases timedAI pregnancy rates in beef cows. Theriogenology 15:843-851.

Chebel, R. C., J. E. P. Santos, R. L. A. Cerri, H. M. Rutigliano, and R. G. S. Bruno. 2006. Reproduction in dairy cows following progesterone insert presynchronization and resynchronization protocols. J. Dairy Sci. 89:4205-4219.

Ferguson, J. D., D. T. Galligan, and N. Thomsen. 1994. Principal descriptors of body condition score in Holstein cows. J. Dairy Sci. $77: 2695-2703$.
Galvão, K. N., M. F. Sá Filho, and J. E. P. Santos. 2007. Reducing the interval from presynchronization to initiation of timed AI improves fertility in dairy cows. J. Dairy Sci. 90:4212-4218.

Gümen, A., J. N. Guenther, and M. C. Wiltbank. 2003. Follicular size and response to Ovsynch versus detection of estrus in anovular and ovular lactating dairy cows. J. Dairy Sci. 86:3184-3194.

Harris, B. L., and E. S. Kolver. 2001. Review of Holsteinization on intensive pastoral dairy farming in New Zealand. J. Dairy Sci. 84(E. Suppl.):E56-E61.

Lima, F. S., H. Ayres, M. G. Favoreto, R. S. Bisinotto, L. F. Greco, E. S. Ribeiro, P. S. Baruselli, C. A. Risco, W. W. Thatcher, and J. E. P. Santos. 2011. Effects of gonadotropin-releasing hormone at the initiation of the 5-d timed artificial insemination (AI) program and timing of induction of ovulation relative to AI on ovarian dynamics and fertility of dairy heifers. J. Dairy Sci. 94:4997-5004.

McDougall, S. 2010. Comparison of diagnostic approaches, and a costbenefit analysis of different diagnostic approaches and treatments of anoestrous dairy cows. N. Z. Vet. J. 58:81-89.

McDougall, S., and C. W. R. Compton. 2006. Reproductive performance in the subsequent lactation of dairy cows previously treated for failure to be detected in oestrus. N. Z. Vet. J. 54:132-140.

Moreira, F., C. Orlandi, C. A. Risco, R. Mattos, F. Lopes, and W. W. Thatcher. 2001. Effects of presynchronization and bovine somatotropin on pregnancy rates to a timed artificial insemination protocol in lactating dairy cows. J. Dairy Sci. 84:1646-1659.

Peters, M. W., and J. R. Pursley. 2003. Timing of final GnRH of the Ovsynch protocol affects ovulatory follicle size, subsequent luteal function, and fertility in dairy cows. Theriogenology 60:11971204.

Rhodes, F. M., S. McDougall, C. R. Burke, G. A. Verkerk, and K. L. Macmillan. 2003. Treatment of cows with an extended postpartum anestrous interval. J. Dairy Sci. 86:1876-1894.

Ribeiro, E. S., R. S. Bisinotto, M. Favoreto, L. T. Martins, R. L. A. Cerri, F. T. Silvestre, L. F. Greco, W. W. Thatcher, and J. E. P. Santos. Reproduction in dairy cows following presynchronization and administration of prostaglandin $\mathrm{F}_{2 \alpha}$ as one or divided in two doses in the 5-d timed artificial insemination protocol. Theriogenology. http://dx.doi.org/10.1016/j.theriogenology.2012.01.012. In press.

Ribeiro, E. S., R. L. A. Cerri, R. S. Bisinotto, F. S. Lima, F. T. Silvestre, M. G. Favoreto, L. F. Greco, W. W. Thatcher, and J. E. P. Santos. 2011. Reproductive performance of grazing dairy cows following presynchronization and resynchronization protocols. J. Dairy Sci. 94:4984-4996.

Santos, J. E. P., C. D. Narciso, F. Rivera, W. W. Thatcher, and R. C. Chebel. 2010. Effect of reducing the period of follicle dominance in a timed AI protocol on reproduction of dairy cows. J. Dairy Sci. 93:2976-2988

Santos, J. E. P., H. M. Rutigliano, and M. F. Sá Filho. 2009. Risk factors for resumption of postpartum cyclicity and embryonic survival in lactating dairy cows. Anim. Reprod. Sci. 110:207-221.

Santos, J. E. P., W. W. Thatcher, R. C. Chebel, R. L. A. Cerri, and K. N. Galvão. 2004. The effect of embryonic death rates in cattle on the efficacy of estrus synchronization programs. Anim. Reprod. Sci. 82-83:513-535.

Siddiqui, M. A. R., E. L. Gastal, M. O. Gastal, M. Almamun, M. A. Beg, and O. J. Ginther. 2009. Relationship of vascular perfusion of the wall of the preovulatory follicle to in vitro fertilization and embryo development in heifers. Reproduction 137:689-697.

Souza, A. H., H. Ayres, R. M. Ferreira, and M. C. Wiltbank. 2008. A new presynchronization system (Double-Ovsynch) increases fertility at first postpartum timed AI in lactating dairy cows. Theriogenology 70:208-215.

Stevenson, J. S. 2011. Alternative programs to presynchronize estrous cycles in dairy cattle before a timed artificial insemination program. J. Dairy Sci. 94:205-217. 